\title{
Methods of Assess the Impact of Technological Variables Complex Spatial-Distributed Systems on Costs
}

\author{
Korneev A. M , Shmyrin A. M. , Lavrukhina T. V., Abdullakh L. S. \\ Lipetsk State Technical University, Rusia
}

\begin{tabular}{l}
\hline \hline Article Info \\
\hline Article history: \\
Received Dec 14, 2015 \\
Revised Feb 15, 2016 \\
Accepted Feb 22, 2016 \\
\hline
\end{tabular}

\begin{abstract}
The paper considers the method of calculating costs, taking into account the effect of technological parameters; the model of forecasting of costs of production resources based on the matrix of costs are described; the methods of assess the impact of parameters of complex spatial-distributed systems on costs are presented.
\end{abstract}

\section{Keyword:}

Complex

Mathematical Model

Method of Calculation,

Process

System

Copyright (C) 2016 Institute of Advanced Engineering and Science. All rights reserved.

\section{Corresponding Author:}

Korneev A. M,

Lipetsk State Technical University,

Rusia.

Email: d.48@rambler.ru

\section{INTRODUCTION}

For analyzing the dependency of costs on the thickness and width of metal, matrices of costs for the particular cost elements and total costs on the stage of processing or assembly can be built. Such matrices are constructed for each steel grade separately.

If the defining technological parameters for all cost elements are known, we can calculate these costs during the study period.

Initial data are:

- The data array on volumes of industrial products $M$;

- Array of the defining technological parameters for each element of $\cos t X^{Z}$;

- Diagonal matrix of the coefficients of proportionality for each element of $\operatorname{cost} K^{Z X}$ (the number of elements of costs P).

In matrix form:

$$
\left(M^{*} X^{(Z)}\right) * K^{(Z X)}=Z
$$

On the first stage of the research, the matrix of proportionality $K^{(Z X)}$ is unknown. Having the initial data for a definite base period (for example, for the month) on production volumes $M_{E}$, processing technologies $X_{B}^{(Z)}$ and expended resources $Z_{B}$, a matrix $K^{(Z X)}$ can be achieved

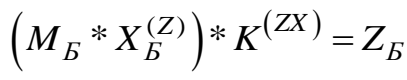

Multiplying by the inverse matrix: 


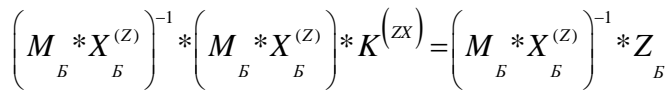

As the result, we have:

$$
K^{(Z X)}=\left(M_{5} * X_{5}^{(Z)}\right)^{-1} * Z_{B}
$$

On the basis of generalized matrices of coefficients of proportionality $K_{\Sigma_{I}}$ and total consumption of technological parameters during the studied period $\operatorname{diag}\left(M * X_{\Sigma}\right)$, it is possible to predict the consumption of resources in the current period according to basic coefficients $[5,7,8]$.

$$
Z_{\sum(\text { study } / \text { base })}=\operatorname{diag}\left(M * X_{\Sigma}\right)_{\text {study }} * K_{\text {Sbase }}
$$

where

$Z_{\sum \text { (study/base) }}$ - is the matrix of total costs during the studied month on the basic;

$\operatorname{diag}\left(M * X_{\Sigma}\right)$ - is a diagonal matrix of the studied period;

$K_{\sum_{b a s e}}-$ is the matrix of coefficients of the base period.

Similarly, the matrix of forecasts on all $I$ studied periods according to the coefficients of proportionality of basic $J$ periods are defined.

$$
Z_{\Sigma(I, J)}=\operatorname{diag}\left(M \cdot X_{\Sigma}\right)_{(I)} \cdot K_{\Sigma(J)}
$$

If $\mathrm{T}$ of periods is explored, then the final matrix of the forecasts will contain $[T$ (the number of matrices $\left.\left.K_{\Sigma(J)}\right)\right]\left[(T-1)\right.$ (the number of predicted periods), i.e $\left.\operatorname{diag}\left(M * X_{\Sigma}\right)_{(I)}\right]=[T *(T-1)]$ lines. The final table for each cost element has the following form (table 1).

Table 1. the Model of Calculation of Cost Items

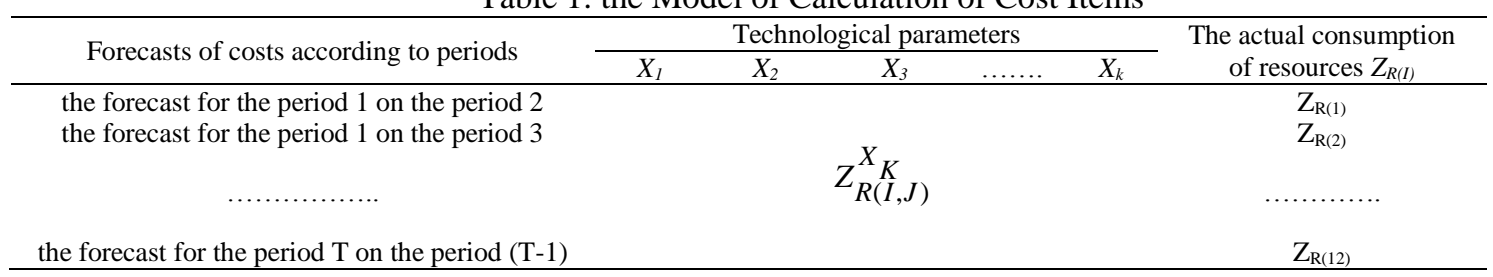

Note to the table 1:

$X_{k}$ - is technological parameter of period $k ; Z_{R(I J)}^{X_{L}}$ - is the value of the forecast for the $J$ period of consumption of the $R$ resource according to the data of the $I$ period in the $X_{k}$ parameter.

To assess the influence of particular parameters on the cost elements, the separate matrices of forecasts for each parameter $X_{n}$ are built (table 2).

Table 2. Matrix of forecasts for the parameter $X_{n}$ on $T$ periods

\begin{tabular}{ccccccc}
\hline Base periods $(J)$ & & \multicolumn{5}{c}{ The studied periods $(I)$} \\
\hline 1 & 1 & $\cdots$ & $J$ & $I$ & $\cdots$ & $T-1$ \\
$\ldots$ & $Z_{R(1)}$ & & & & & \\
$J$ & & & & & & \\
$\ldots$ & & & & & \\
$R(J)$ & $Z_{R(\text { InoJ })}$ & & \\
$T-1$ & & & & & \\
$T$ & & & & & $Z_{R(T)}$ \\
\hline
\end{tabular}

If the numbers of the base and studied periods are equal $(\mathrm{I}=\mathrm{J})$ in the table 2 , then $Z_{R(\text { InoJ })}$ the actual consumption of resources during the studied period $Z_{R(J)}$ is noted. As the result, it is possible to get average 
forecasts for particular periods and for the entire studied period (e.g. a year). The average error of forecasts for the period on the studied parameter $X_{L}$ :

$$
\bar{\varepsilon}_{R(I)}^{X_{L}}=\frac{\sum_{J=1}^{T}\left|\frac{Z_{R(I)}-Z_{R(I J)}^{X_{L}}}{Z_{R(I)}}\right|}{T}
$$

Where: $Z_{R(I)}$ - is the actual consumption of resource R during the studied period $I$;

$Z_{R(I J)}^{X_{L}}$ - are projected costs of the $R$ resource on a complex of $X_{L}$ parameters for the $I$ period in the matrix of basic coefficients for the $J$ period;

$T-$ is the number of projected periods.

The average error for the entire projected period for each technological parameter

$$
\bar{\varepsilon}_{R}^{X_{L}}=\frac{\sum_{i=1}^{I} \bar{\varepsilon}_{R(I)}^{X_{L}}}{I}
$$

An example of a forecast of resource consumption depending on technological parameters is given in the table 3 .

Table 3. The Forecast of Electric Energy Consumption on the Total Compression, $\mathrm{kW} h$

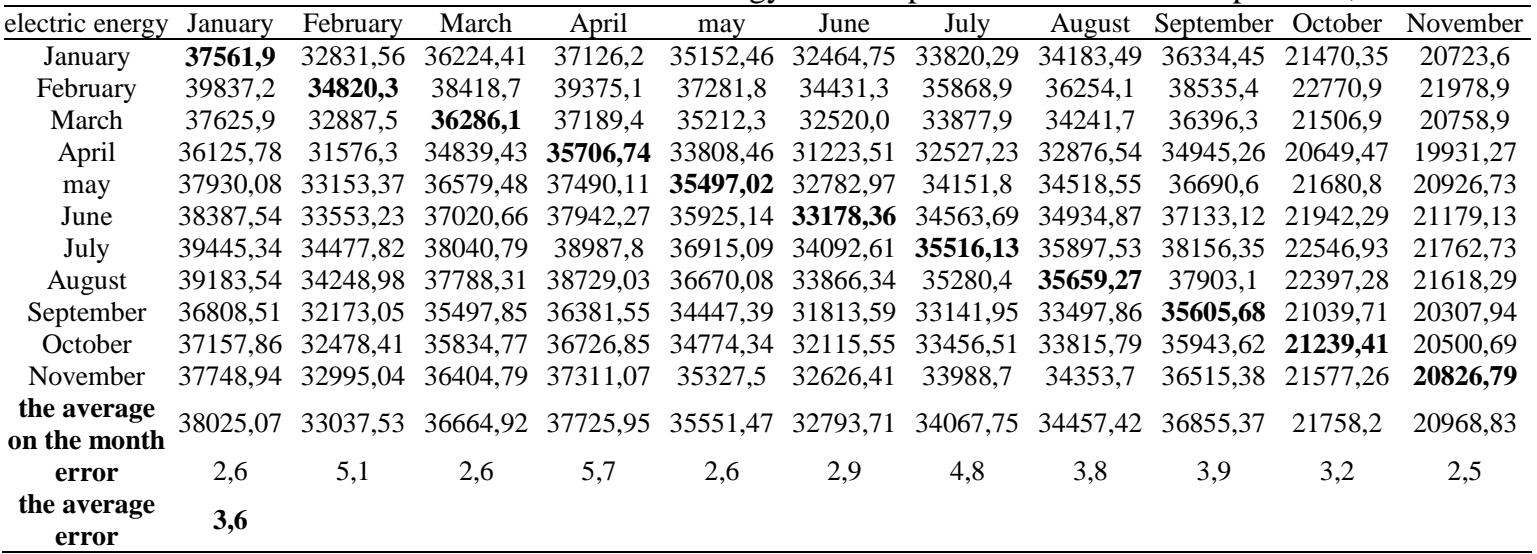

Using the data of the table 1 it is possible to construct a regression model of dependency of the actual consumption of resources from the predicted values of technological parameters.

$$
Z_{i}=b_{0}+\sum_{j=1}^{K} b_{j} \cdot Z_{i(I, J)}^{X}, i=1, \ldots, R
$$

Since the values of actual and projected consumption of resources are comparable in size, the coefficients of the $b_{j}$ model allow estimating the impact of the predicted value of the cost element according to the corresponding technological parameter on the real value of the studied resource $[1-4,6,8]$. It is possible to evaluate the effectiveness of the use of particular parameters for the cost forecast by receiving correlation matrix in the table 1.

Correlation and regression analyses allow estimating the influence of parameters without getting $Z_{i}^{X_{j}}$ forecasts. In this case, it is possible to evaluate the influence of the total consumption of each technological parameter $\sum_{n} M X_{k}$ on the cost elements. Table 4 is formed here. 
Table 4. Total Consumption of Technological Parameters and the Cost Elements

\begin{tabular}{|c|c|c|c|c|c|c|c|c|c|c|}
\hline \multirow[t]{2}{*}{ period } & \multirow[t]{2}{*}{ products } & \multirow[t]{2}{*}{ weight } & \multicolumn{3}{|c|}{$\begin{array}{l}\text { technological } \\
\text { parameters }\end{array}$} & \multicolumn{2}{|c|}{$\begin{array}{l}\text { Total consumption of technological } \\
\text { parameters } \sum_{i=1}^{n} m_{i} x_{j i}\end{array}$} & \multicolumn{3}{|c|}{ the cost elements } \\
\hline & & & $X_{1}$ & $\ldots$ & $X_{K}$ & $X_{1}$ & $X_{K}$ & $Z_{1}$ & $\ldots$ & $Z_{P}$ \\
\hline 1 & $\begin{array}{l}1 \\
\ldots \\
n\end{array}$ & $\begin{array}{c}m_{11} \\
\cdots \\
m_{n 1}\end{array}$ & $\begin{array}{l}x_{11} \\
\cdots \\
x_{1 n}\end{array}$ & & $\begin{array}{c}x_{K 1} \\
\ldots \\
x_{K n}\end{array}$ & $\left(\sum_{i=1}^{n} m_{i} x_{1 i}\right)_{1}$ & $\left.\sum_{i=1}^{n} m_{i} x_{K i}\right)_{1}$ & $Z_{11}$ & & $Z_{P 1}$ \\
\hline $\mathrm{T}$ & $\begin{array}{l}1 \\
\ldots \\
\mathrm{n}\end{array}$ & $\begin{array}{c}m_{1 T} \\
\cdots \\
m_{n T}\end{array}$ & $\begin{array}{l}x_{11} \\
\ldots \\
x_{1 n}\end{array}$ & & $\begin{array}{c}x_{K 1} \\
\ldots \\
x_{K n}\end{array}$ & $\left(\sum_{i=1}^{n} m_{i} x_{1 i}\right)_{T}$ & $\left.\sum_{i=1}^{n} m_{i} x_{K i}\right)$ & $Z_{1 T}$ & & $Z_{P T}$ \\
\hline
\end{tabular}

The mass of products, which is realized for all the elements of the alphabets $b_{k j_{k}}$ of these parameters $m_{b_{k j_{k}} t}$ during the studied period $t$ (table 5), is determined to assess the impact of technological factors on the consumption of resources.

Table 5. The Distribution of Mass of Products According to Elements of the Alphabets of the Parameters

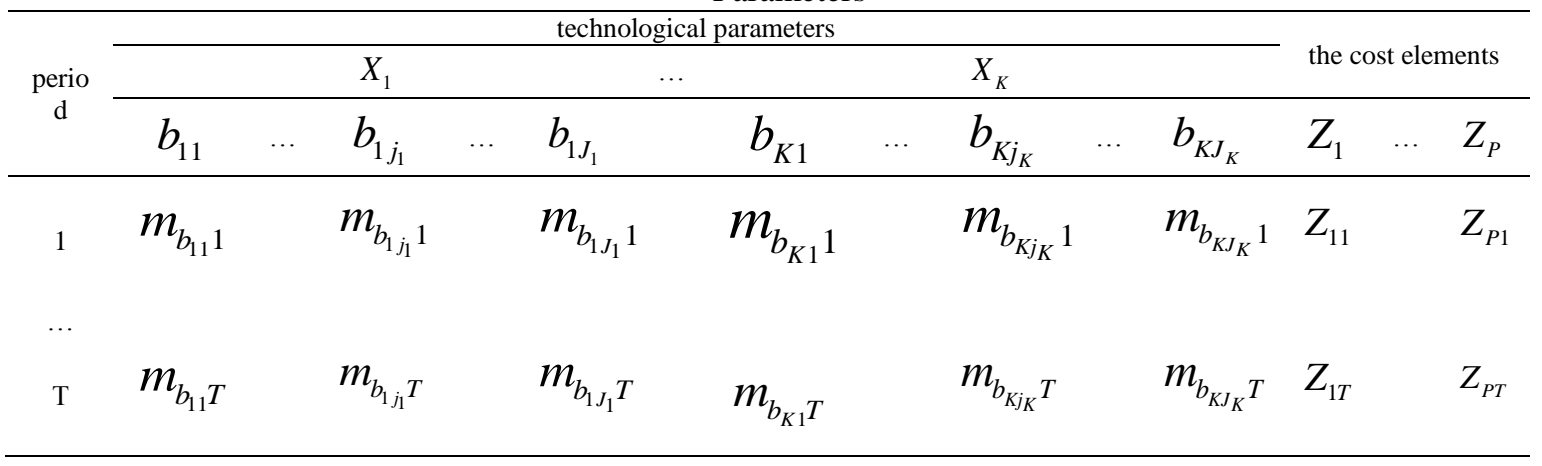

According to the obtained data from the table 5, it is possible to construct models of forecast of the resource consumption from "total consumption" of technological parameters according to their distribution on the alphabet elements.

$$
Z_{p}=c_{0}+\sum_{k=1}^{K} \sum_{j_{k}=1}^{J_{k}} c_{k j_{k}} m_{b_{k j_{k}}} \tilde{b}_{k j_{k}}, p=1, . ., P
$$

where $\tilde{b}_{k j_{k}}$ - is the average value of the alphabet element

\section{CONCLUSIONS}

a. The algorithms and models of requirement forecast in the resources for production are developed, allowing to provide us with a more detailed cost information and to help in price fixing for different types of products, significantly reducing response times to changing economic and technological situation.

b. Methods of evaluation the impact of parameters of complex spatial-distributed systems on costs are introduced. 


\section{REFERENCES}

[1] Korneev A. M., Abdullakh L. S. Smetannikova T. A. Simulation of difficult industrial systems in the form of the probable automatic machine // Metallurgical and Mining Industry, 2015, no.2, pp. 257-261.

[2] Abdullakh L. S., Smetannikova T. A., Korneev A. M. Criterion for assessing the effectiveness of functioning of complex systems based on the use the amount of information. International Journal of Applied Engineering Research. 2015. T. 10. No. 11. C. 27961-27980.

[3] Korneev A. M., Abdullakh L. S. Smetannikova T. A. The calculation of costs for oxygen-Converter production. Fundamental and applied studies in the modern world. 2015. no. 9-1. C. 52-55.

[4] Korneev A.M. Miroshnikova T.V. Evaluation of the influence of cost of production using the evaluation criteria of optimality of technological modes. Socio-economic processes or phenomena. 2011. no. 1-2 (23-24). C. 113-115.

[5] Korneev A. M. Miroshnikova T. V. Development of models for analysing the economic performance of complex industrial systems. Socio-economic processes or phenomena. 2010. no. 6 (22). C. 87-91.

[6] Korneev A.M. Criteria communication technologies and properties, taking into account costs and the cost of the finished product. Management systems and information technology. 2008. T. 31. no. 1.1. C. 160-162.

[7] Korneev A.M. Miroshnikova T.V. The method of calculating costs taking into account the influence of technological factors. Management systems and information technology. 2007. T. 30. No. 4.2. C. 251-255.

[8] Korneev A.M., Bolotova T.V. Analysis of the requirements for the production of steel at change of production conditions. Management systems and information technology. 2006. T. 26. № 4.2. C. 241-245. 